\title{
Adsorption Characteristics of Al (III), Ni (II), Sm (III) Ions on Resin with Styrene Hazardous Material in Reinforcement Water Fire Extinguishing Agent
}

\author{
Joon-Tae Kim ${ }^{\dagger}$
}

\begin{abstract}
The ion exchange resins were synthesized from 1-aza-18-crown-6 macrocyclic ligand attached to styrene (2th petroleum in 4th class hazardous material) divinylbenzene (DVB) copolymer with crosslinks of $1 \%, 6 \%$, and $15 \%$ by substitution reaction. These synthetic resins were confirmed by chlorine content, elementary analysis, surface area, and IR-spectrum. The object of this study was to seperate the metal ion absorbed in reinforcement water fire extinguishing agent. As the results of the effects of $\mathrm{pH}$, equilibrium arrival time, and crosslink of synthetic resin on metal ion adsorption for resin adsorbent, the metal ions were showed high adsorption at $\mathrm{pH} 3$ or over and adsorption equilibrium of metal ions was about 2 hours. In addition, adsorption selectivity for the resin in water was the order of Al (III) $>\mathrm{Ni}$ (II) $>$ Sm (III) ions, adsorbability of the metal ions was in the crosslinks order of $1 \%, 6 \%$, and $15 \%$.
\end{abstract}

Key words: Reinforcement Water, Macrocyclic, Styrene, Resin, Adsorption

\section{Introduction}

Macrocyclic compounds comprise alkali, alkaline earth metal, transition metal, heavy metal ions and stable complexes ${ }^{[1]}$ by the properties of donor atom forming a ring. A method for separating metal ions from these kinds of complexes was initiated from the studies on the equilibrium of a solvent extraction system ${ }^{[2]}$.

Grimsley et al.$^{[3]}$ synthesized a chain of nitrogen-oxygen donor (cryptand) macrocyclic ligands, and examined complex formation of the ligands, transition metal ions and post-transition metal ions for finding the macrocyclic ligands to select specific metal ions and for verifying the causes to exist the selectivity.

Moreover, whereas a method to separate metal ions by using neutralization or precipitation gives a low separating effect due to high solubility of the metal ions and has some technical difficulties, another method to adsorb and separate the metal ions by using minerals is being used as a variety of forms because of easy appli-

Department of Herb Material Industry, Dongshin University, Naju, 520714, South Korea

${ }^{\dagger}$ Corresponding author : kjt7614@hanmail.net

(Received: July 19, 2013, Revised : September 16, 2013 Accepted : September 23, 2013) cation without requiring high technology or complicated equipment ${ }^{[4]}$.

Bombieri et al. ${ }^{[5]}$ identified the structure of lanthanoid and uranium complexes through X-ray analysis, and verified that all oxygen atoms on a same plane are combined with uranium ions. Meanwhile, studies have been actively under way for preventing environmental contamination due to the loss of toxicant macrocyclic compounds possibly produced in the chromatography moving the solvent extraction or the macrocyclic compounds into a fixed phase or a mobile phase ${ }^{[6,7]}$, and for developing a separation method with an excellent separating effect. Blausius et al. ${ }^{[8]}$ synthesized resins by condensing various macrocyclic compounds and formaldehyde, or copolymerizing divinylbenzene and macrocyclic compounds containing vinyl radicals. They also substituted cryptand series for styrene-1,4-divinylbenzene (styrene-DVB), and studied the separation of metal ions by using these resins. And, cryptand series resin and metal ion adsorption are dependent on the characteristics of ion diameter-cavity radius.

Styrene ${ }^{[9]}$ is 2 th petroleum in 4 th class hazardous materials, as a colorless and toxic benzene derivatives, it has a distinctive smell. It dissolves in alcohol, ether and carbon disulfide is insoluble in water. It forms a 
colorless solid matter by polymerization.

$\mathrm{K}_{2} \mathrm{CO}_{3},\left(\mathrm{NH}_{4}\right)_{2} \mathrm{SO}_{4},\left(\mathrm{NH}_{4}\right)_{3} \mathrm{PO}_{4}$ are added to drop the freezing point of the reinforcement water fire extinguishing agent, the reinforcement water fire extinguishing agent becomes ineffective due to precipitation made of $\mathrm{Al}_{2}\left(\mathrm{SO}_{4}\right)_{3}, \mathrm{AlPO}_{4}$ or $\mathrm{NiSO}_{4}, \mathrm{Ni}_{3}\left(\mathrm{PO}_{4}\right)_{2}$ when aluminium, nickel, samarium ions are dissolved in water.

Therefore, this study synthesized ${ }^{[10]}$ the chloromethylated styrene-DVB copolymer available to selectively separate and adsorb metal ion in reinforcement water fire extinguishing agent. Hereupon, the chloromethylated copolymers were chemically combined with 1-aza18-crown-6 (1-aza-18-C-6) macrocyclic ligand to produce a new functional resin, and then, the adsorption $^{[11-16]}$ of $\mathrm{Al}$ (III), Ni (II), and Sm (III) ions was examined.

\section{Experimental Section}

\subsection{Materials}

Samarium nitrate, 1-aza-18-crown-6, and styrene were purchased from Aldrich Co., special grade 1,4divinylbenzene (55\%), 1,4-dioxane and benzoyl peroxide were bought from Donggyeong Co, Hwaseong Co, and aluminium nitrate, nickel nitrate, benzene, toluene, potassium iodide, etc. were used with general reagents.

An infrared ray spectrum was analyzed through Shimadzu IDP-440 A, and element analysis was performed using Model 1108 of Carlo-Erba Co. and surface area was measured using Nanoporosity-XQ of Mirae SI Co. and $\mathrm{pH}$ was measured through a calomel glass electrode of Corning $\mathrm{pH}$ meter 320, and a quantitative analysis of $\mathrm{Cl}^{-}$was conducted by Orion chloride ion-selective electrode. The aluminium, nickel, and samarium ions were measured through ICP-AES (Inductively Coupled Plasma Atomic Emission Spectrometer) Lab-test 710 type and Coleman spectrophotometer $(350 \sim 750 \mathrm{~nm})$.

\subsection{Synthesis of Styrene-DVB Copolymer}

For the synthesis ${ }^{[10]}$ of styrene-DVB copolymer, a $500 \mathrm{~mL}$ triple mouth flask equipped with a reflux condenser and a thermometer was connected with a nitrogen gas injection tube, and was installed with an apparatus to confirm the stirring speed. Distilled water $250 \mathrm{~mL}$ was added into the triple mouth flask. The added amount of resin was varied according to the crosslinks such as follows : styrene $99 \mathrm{~mL} / \mathrm{DVB} 1.8 \mathrm{~mL}$ for $1 \%$ of the crosslink, styrene $94 \mathrm{~mL} / \mathrm{DVB} 10.8 \mathrm{~mL}$ for $6 \%$, styrene $85 \mathrm{~mL} / \mathrm{DVB} 27.0 \mathrm{~mL}$ for $15 \%$. Benzoyl peroxide $1 \mathrm{~g}$ as an initiation reagent, $\mathrm{NaCl} 10 \mathrm{~g}$ as stabilizer, gelatin $0.5 \mathrm{~g}$ and Arabic rubber $1.5 \mathrm{~g}$ were added and stirred at 1,200 rpm with being reacted at $90^{\circ} \mathrm{C}$ for 8 hours, and then cooled. Supernatant was removed, and the copolymer was washed with methanol, distilled water and methanol in order.

\subsection{Chlorination of Copolymer}

Styrene-DVB copolymer was dried at $110^{\circ} \mathrm{C}$ for more than 12 hours, and $5 \mathrm{~g}$ of which and $100 \mathrm{~mL}$ of chloroether were swollen at room temperature for 2 hours in a $250 \mathrm{~mL}$ flask. Zinc chloride $2 \mathrm{~g}$ was dissolved in chloroether $25 \mathrm{~mL}$, which was added to and placed in the flask. The supernatant was removed, and $100 \mathrm{~mL}$ of dioxan-distilled water mixture (70:30) was added to the flask and stirred for an hour for washing the copolymers during the stirring process. Then, the washed copolymers were dried at 50 for 3 days.

\subsection{Function Reaction of Copolymer}

Each $2.83 \mathrm{~g}$ of chloromethylated $1 \%, 6 \%$, and $15 \%$ styrene-DVB copolymers was mixed with $50 \mathrm{~mL}$ of benzene, and then stirred, refluxed and swollen at boiling temperature for 2 hours. After remaining benzene was removed, $50 \mathrm{~mL}$ of toluene, $0.75 \mathrm{~g}$ of $\mathrm{KI}$ and 2.63 $\mathrm{g}$ of 1-aza-18-C-6 macrocyclic ligand were added, stirred and refluxed at $55^{\circ} \mathrm{C}$ for 30 hours under nitrogen condition, which was cooled at room temperature and filtered. The washing process was conducted with $2 \mathrm{M}$ hydrochloric acid, distilled water, $1 \mathrm{M}$ sodium hydroxide and distilled water in order. Finally, the copolymer was washed several times with methanol and then dried in the air, to get 1-aza-18-C-6-styrene-DVB resin (after called resin) having $1 \%, 6 \%$, and $15 \%$ crosslinks. The size of resin cavity was 200-400 mesh.

\subsection{Experimental Method}

It was measured to take the content of chloro according to crosslink in the process of synthesizing the resin using chloride ion-selective electrode and the surface area to check the porosity according to the crosslink. It was confirmed that the synthesis of resins is a IR-spectrum due to $\mathrm{KBr}$ disc method and the ultimate resins that each is composed of $1 \%, 6 \%$, and $15 \%$ crosslinks analyzed the content of elements like C, H, N, O using 
elementary analysis. Also, $\mathrm{Al}\left(\mathrm{NO}_{3}\right)_{3}, \mathrm{Ni}\left(\mathrm{NO}_{3}\right)_{2}$, and $\mathrm{Sm}\left(\mathrm{NO}_{3}\right)_{3}$ solutions of $3.0 \mathrm{mM}$ were controled the $\mathrm{pH}$ by dilute nitric acid or sodium hydroxide to investigate the adsorption character of metallic ion according to $\mathrm{pH}$, equilibrium arrival time, crosslink.

The resin having $1 \%$ crosslink was added $1 \mathrm{~g}$ to each solution, and solutions were filtered after being stirred for two hours in room temperature. Each ion of aluminium, nickel, samarium was quantitatively analyzed using ICP-AES under the circumstances of dilute nitric acid.

\section{Results and Discussion}

\subsection{Confirmation of Resin}

Styrene-DVB copolymer was synthesized ${ }^{[10,12,15]}$ as shown in Scheme 1 through suspension polymerization in an aqueous solution with benzoyl peroxide as an initiation reagent that is commonly used to synthesize conventional polymerized-type ion exchange resin.

To measure the content of chlorine according to crosslinks during the copolymerization, $\mathrm{HCl}$ produced
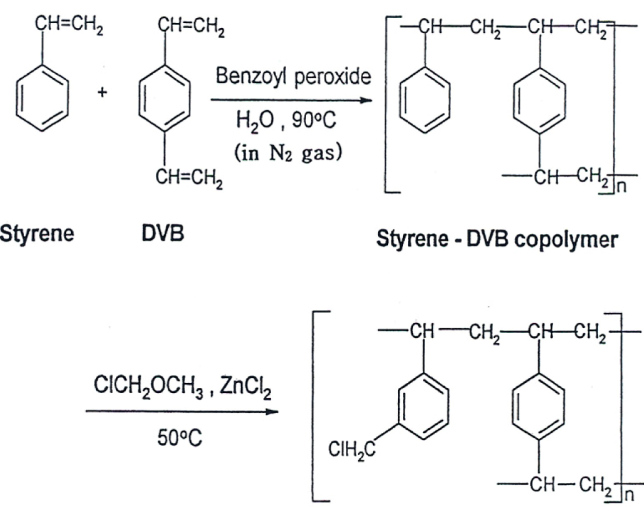

Chloromethylated styrene-DVB copolymer

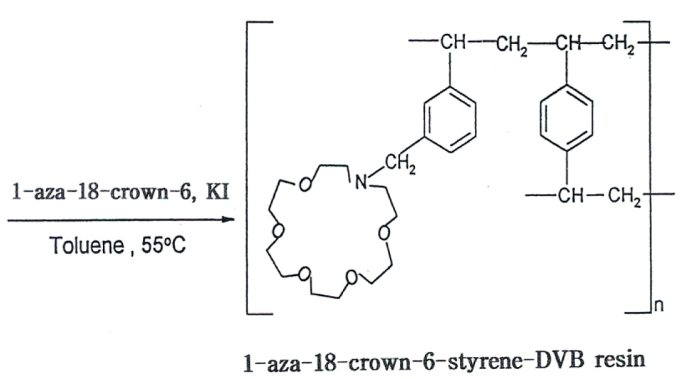

Scheme 1. Synthetic process of resin. through heat hydrolysis was absorbed into distilled water, and the chlorine content was measured using chlorine ion-selective electrode as shown in Table 1. With the increase of the crosslink, the chlorine content was decreased. This can be understood by the fact that the increase of the crosslink increased the DVB content and consequently increased the crosslink density, and also the porosity according to the increase of the crosslink density of copolymers became lower and reduced the chlorine content during the substitution reaction.

Table 2 is an IR-data obtained through $\mathrm{KBr}$ disc method. As a result that the chloromethylated styreneDVB copolymer was combined with 1-aza-18-C-6, the 1-aza-18-C-6 was maybe displaced because there were no N-H

peak near $3400 \mathrm{~cm}^{-1}$ and $\mathrm{C}-\mathrm{Cl}$ absorption peak around $700 \mathrm{~cm}^{-1}$. Moreover, the induction of the macrocyclic ligand brought stretching vibration peaks of strong and wide C-O-C and C-N-C in $1260 \mathrm{~cm}^{-1}$, and a new stretching vibration peak of sharp $\mathrm{C}-\mathrm{N}$ in $1030 \mathrm{~cm}^{-1}$.

Table 1. Chlorine contents in copolymer

\begin{tabular}{cc}
\hline Degree of crosslinking (\%) & $\mathrm{Cl}(\%)$ \\
\hline 1 & 12.35 \\
6 & 10.18 \\
15 & 10.02 \\
\hline
\end{tabular}

Table 2. IR-data of $1 \%, 6 \%$, and $15 \%$ crosslinked styreneDVB copolymer (A), 1-aza-18-C-6 (B), and 1\% crosslinked resin $(\mathrm{C})$

\begin{tabular}{|c|c|c|c|}
\hline \multirow{2}{*}{$\begin{array}{l}\text { Kinds of resin } \\
\text { function group }\end{array}$} & \multicolumn{3}{|c|}{ Frequency $\left(\mathrm{cm}^{-1}\right)$} \\
\hline & (A) & (B) & (C) \\
\hline $\mathrm{N}-\mathrm{H}$ & --- & 3400 & --- \\
\hline $\begin{array}{l}\text { Aromatic } \\
(\mathrm{C}-\mathrm{H})\end{array}$ & $3000-3100$ & --- & $3000-3100$ \\
\hline $\begin{array}{l}\text { Aliphatic } \\
\text { (C-H) }\end{array}$ & $2850-2950$ & $2800-2950$ & $2850-2950$ \\
\hline $\begin{array}{l}\text { Benzene ring } \\
\text { (CC) }\end{array}$ & $1450-1500$ & --- & $1450-1500$ \\
\hline $\begin{array}{l}\mathrm{C}-\mathrm{O}-\mathrm{C} \\
\mathrm{C}-\mathrm{N}-\mathrm{C}\end{array}$ & --- & $1050-1150$ & 1260 \\
\hline $\begin{array}{l}\text { Mono Substition } \\
\quad \text { (4 peaks) }\end{array}$ & $1700-2000$ & --- & $1700-2000$ \\
\hline $\mathrm{C}-\mathrm{Cl}$ & 700 & --- & --- \\
\hline $\mathrm{C}-\mathrm{N}$ & --- & --- & 1030 \\
\hline
\end{tabular}


Table 3. Compositions of resins with various crosslinked

\begin{tabular}{ccccc}
\hline \multirow{2}{*}{$\begin{array}{c}\text { Degree of } \\
\text { crosslinking (\%) }\end{array}$} & \multicolumn{4}{c}{ Resin } \\
\cline { 2 - 5 } & $\mathrm{C} \%)$ & $\mathrm{H} \mathrm{( \% )}$ & $\mathrm{N} \mathrm{( \% )}$ & $\mathrm{O} \mathrm{( \% )}$ \\
\hline 1 & 73.05 & 8.51 & 2.75 & 15.69 \\
6 & 73.16 & 8.57 & 2.52 & 15.75 \\
15 & 73.28 & 8.66 & 2.16 & 15.90 \\
\hline
\end{tabular}

Table 4. Surface area and pore volume of resin

\begin{tabular}{ccc}
\hline $\begin{array}{c}\text { Degree of } \\
\text { crosslinking }(\%)\end{array}$ & $\begin{array}{c}\text { Surface area } \\
\left(\mathrm{m}^{2} / \mathrm{g}\right)\end{array}$ & $\begin{array}{c}\text { Pore volume } \\
\left(\mathrm{cm}^{3} / \mathrm{g}\right)\end{array}$ \\
\hline 1 & 14.75 & 0.0283 \\
6 & 8.90 & 0.0148 \\
15 & 7.32 & 0.0083 \\
\hline
\end{tabular}

Chloroether acts as chloromethylation agent and solvent in a chloromethylation process. Because the copolymers having $1 \%$ crosslink was greatly swollen by chloroether, the copolymer lost a round shape and turned into a distorted shape due to the gelation during the reaction. The chloromethylated copolymers express a light yellowish white color when the $1 \%$ crosslink, but the copolymers of $6 \%$ and $15 \%$ crosslinks are shown to be light brown.

In addition, Table 3 exhibited the results of the resin synthesis according to the size of crosslink and the elementary analysis. When the crosslink became increased, the nitrogen content was decreased. As the results shown like this, the increase of the crosslink also brought on the increase of the DVB content, which subsequently decreased the chlorine content during the substitution reaction because the porosity was lowered due to the increase of crosslink density. Consequently, this influenced the macrocyclic ligand to be displaced, and caused the decrease of the nitrogen content.

The surface area was measured in Table 4 to know the porosity of resin, one of absorsive property. After decompressing and drying the 1-aza-18-C-6-styreneDVB resin composing $1 \%, 6 \%, 15 \%$ of crosslink made in this experiment in $150^{\circ} \mathrm{C}$ for 30 minutes and the surface area was exhibited under the circumstances of nitrogen adsorption method and $-190^{\circ} \mathrm{C}$ by using Nanoporosity-XQ that the surface area and pore volume got lower as the degree of crosslink got bigger, which was reported in the study of Howdle ${ }^{[17]}$.

\subsection{Effects of $\mathrm{pH}$}

To confirm the acidic zone possible to adsorb metal

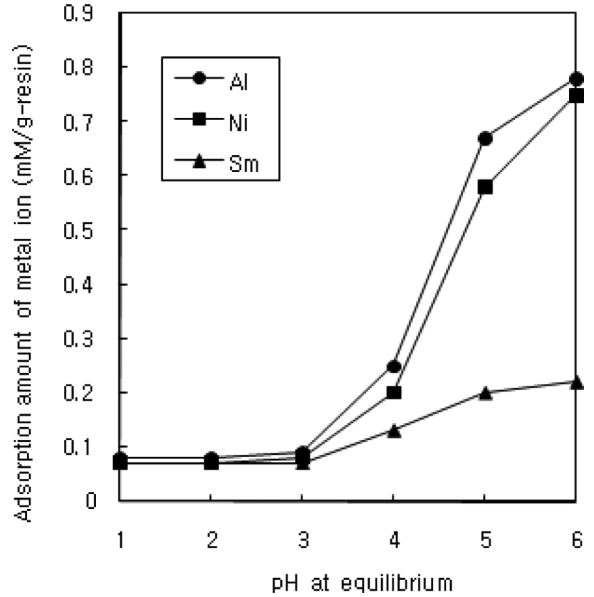

Fig. 1. Adsorption amount of $\mathrm{Al}$ (III), Ni (II), and Sm (III) ions on $1 \%$ crosslinked resin at various $\mathrm{pH}$ in water (concentration : $3.0 \mathrm{mM}$, time : $2 \mathrm{~h}$ ).

ions for the resin aluminium, samarium, and nickel ions of $3.0 \mathrm{mM}$ were stirred in water for 2 hours, and the adsorption characteristics were examined according to the $\mathrm{pH}$ changes of the resin representatively having $1 \%$ of crosslink as shown in Fig. 1. The adsorbability of aluminium ion and nickel ion was gradually increased between $\mathrm{pH} 3$ and $\mathrm{pH} 4$, and the stable complexes of aluminium and nickel was suddenly increased at $\mathrm{pH} 4$ or over.

This phenomenon can be explained by the assumption that because the cryptand resin is basic amine, the nitrogen atom of the resin becomes protonated in a strong acidic solution $(\mathrm{pH}<2)$ and obstructs the adsorption of the metal cations, however, aluminium and nickel ions with the products generated from hydrolysis of the non-protonated resin form stable complexes ${ }^{[11]}$ and yield high adsorptivity in a weak acidic solution $(\mathrm{pH}>3)$. On the other hand, samarium ion cannot form a complex even in a strong acidic zone, and the complex formation is not easy because +3 value rare earth element ions are strongly hydrated and this hydration energy ${ }^{[18]}$ should be overcome to form cryptand resin and complexes. The cryptand resin used in the current study was alkaline, and therefore, the adsorption experiment was performed only in the acidic solution under pH 6.

\subsection{Effects of Equilibrium Arrival Time}

One of necessities to be resin is to quickly reach the 


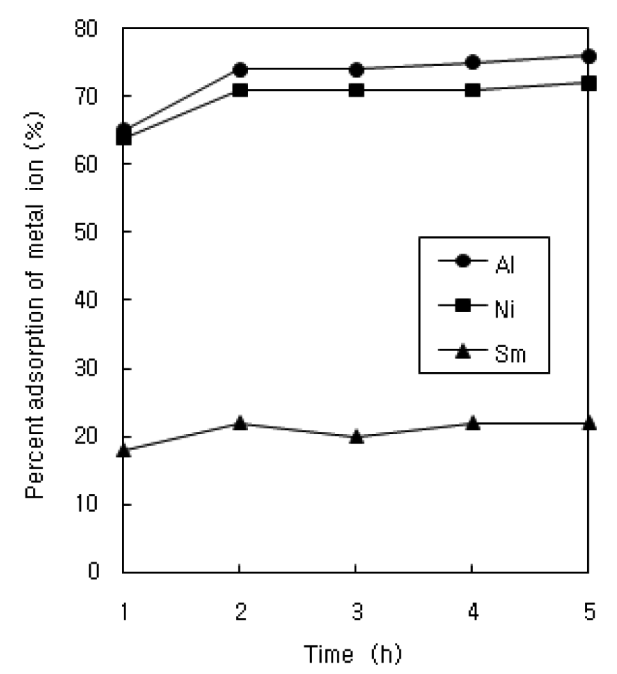

Fig. 2. Adsorption rate of $\mathrm{Al}$ (III), Ni (II), and $\mathrm{Sm}$ (III) ions on $1 \%$ crosslinked resin at various time in water (concentration : $3.0 \mathrm{mM}, \mathrm{pH}: 6$ ).

adsorption equilibrium. Accordingly, Fig. 2 showed the adsorption equilibrium time of aluminium, samarium and nickel ions of $3.0 \mathrm{mM}$ taken to reach the resin having $1 \%$ crosslink in water of $\mathrm{pH} 6$. The adsorptivities were as large as $74 \%$ and $72 \%$ each for aluminium and nickel ions easily forming resin and complexes ${ }^{[11]}$, but $22 \%$ for samarium ion that did not form the cryptand resin and complexes well. Also, the adsorbability of each metal ion to the resin showed to decrease in an order of aluminium $>$ nickel $>$ samarium ions. In investigating the ratios of the size of $\mathrm{Al}(1.85 \AA), \mathrm{Ni}(2.03 \AA)$, and $\operatorname{Sm}(2.20 \AA)$ ions to the resin $(3.0 \AA)$ by a theory ${ }^{[19]}$ that the electrostatic attraction is very large and forms the stable complexes well when the ratios of the metal ion size to the resin cavity is between $0.7 \sim 0.9$ the ratios were $0.62(\mathrm{Al}), 0.68(\mathrm{Ni})$, and $0.73(\mathrm{Sm})$ and seemed to form the complexes very well, however, samarium ion showed low adsorption owing to an influence of hydration energy. Moreover, these kinds of metal ions have the addition of covalent bonds by electrostatic bonding and resin nitrogen atom during the formation of $1 \%$ resin and complexes regardless of the adsorbability, and accordingly, the metal ions easily reach the adsorption equilibrium only after 2 hours. On account of this, not only the conception of ion diameter-cavity radius but also the covalent bond between metal ions and resins and the hydration energy of metal ions react complicately in a case of cryptand-type metal com- plexes having nitrogen donor atom.

\subsection{Effects of Resin Crosslink}

Fig. 3 shows the adsorption amount of aluminium and nickel ion investigated by using the resins having $1 \%, 6 \%$, and $15 \%$ crosslinks through a variation of aluminium and nickel ion concentrations within a range from $1.0 \sim 6.0 \mathrm{mM}$ by water.

As shown in Fig. 3, the resin having 1\% crosslink adsorbed approximately $0.5 \mathrm{mM} / \mathrm{g}$-resin in $1.0 \mathrm{mM}$ whereas the resins having $6 \%$ and $15 \%$ crosslinks adsorbed $0.1 \mathrm{mM} / \mathrm{g}$-resin only. The result of the adsorption presenting as $1 \%>6 \%>15 \%$ resins can be considered due to the reason that the crosslink is dependent on the amount of DVB during the synthesis of styreneDVB copolymers, and the resin crosslink density is decreased with the decrease of the DVB content, whereas the porosity becomes higher and the diffusion velocity of metal ion into the resin is large in the $1 \%$ resin compared with the $6 \%$ and $15 \%$ resins. However, the $6 \%$ and $15 \%$ resins adsorbed at almost the same level as the $1 \%$ resin within the high range $(6.0 \mathrm{mM})$ of metal ion.

A point expressing the maximum adsorption observed in an adsorption curve of Fig. 3 is the apparent capacity of resins. The apparent capacity of aluminium and nickel ion for $1 \%, 6 \%$, and $15 \%$ resins were 0.78 ,

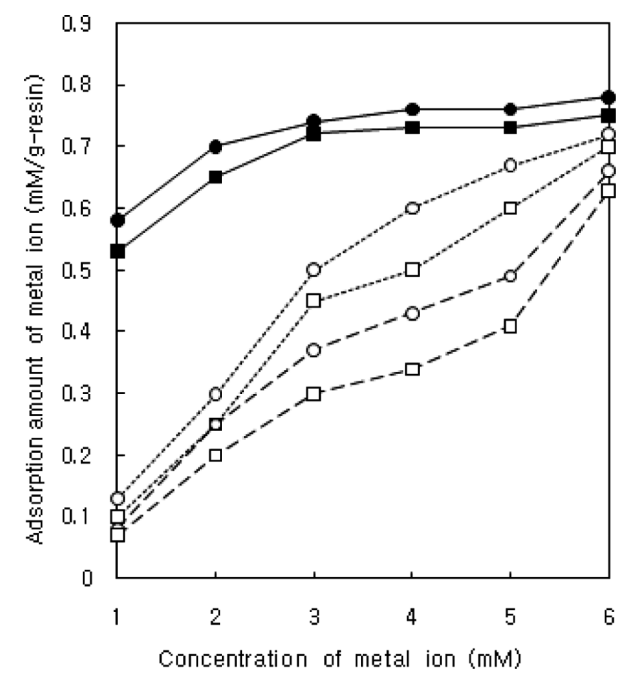

Fig. 3. Adsorption amount of $\operatorname{Al}(\boldsymbol{O}, \bigcirc)$ and $\mathrm{Ni}(\boldsymbol{\square}, \square)$ ions on $1 \%(-), 6 \%(\cdots)$, and $15 \%(--)$ crosslinked resin at various concentration in aluminium and nickel ion (time : $2 \mathrm{~h}, \mathrm{pH}: 6$ ). 
$0.72,0.66$ and $0.75,0.70,0.63 \mathrm{mM} / \mathrm{g}$-resin respectively.

\section{Conclusion}

To selectively separate and adsorb metal ion, resin with styrene hazardous material was synthesized and its adsorption was examined according to diverse conditions. The results are as follows.

The increase of crosslinks in synthetic resin leads to the increase of crosslink density but the lowering of porosity, and subsequently, the chlorine content is reduced. This course influences the macrocyclic ligand, which reduced the nitrogen content.

The nitrogen atom in synthetic resins was protonated under water solution and $\mathrm{pH} 2$ or lower (strong acid) and inhibited the adsorption of metal ion, but metal ion showed high adsorptivity through the formation of stable complexes with the products by the hydrolysis of non-protonated resins, at $\mathrm{pH} 3$ or over (toward weak acid).

The metal ion adsorbability for the resin was shown to be aluminium $>$ nickel $>$ samarium ions, which is affected by a ratio of metal ion to resin cavity, covalent bond between metal ion and resin, and hydration energy of metal ions. Also, the electrostatic bond and the covalent bond by resin nitrogen atom are added when the resin and metal ion form complexes, and therefore, the adsorption equilibrium can be quickly reached only 2 hours passed.

The resins having $1 \%$ crosslink have lower crosslink density and higher porosity due to the small amount of the DVB content than the resins with $6 \%$ and $15 \%$ crosslinks. Accordingly, the diffusion velocity of metal ion into the resin was large even in a dilute solution, which makes it well to adsorb metal ion.

In a series of results, solid membrane resin of macrocyclic compounds is considered to use to recovery and seperate metal ions in reinforcement water fire extinguishing agent.

\section{References}

[1] K. W. Chi, Y. S. Ahn, K. T. Shim, H. Huh, and J. S. Ahn, "Synthesis of diazacrown ethers containing phenolic side arms and their complex with divalent metal ions", Bull. Korean Chem. Soc., Vol. 23, No. 5, pp. 688-692, 2002.
[2] H. K. Frensdorff, "Salt complexes of cyclic polyethers. Distribution equilibria", J. Am. Chem. Soc., Vol. 93, No. 19, pp. 4684-4688, 1971.

[3] P. G. Grimslery, L. F. Lindoy, H. C. Lip, R. J. Smith, and J. T. Baker, "Synthesis of new 14-, 15- and 16membered crown compounds containing oxygen and nitrogen heteroatoms", Aust. J. Chem., Vol. 30, pp. 2095-2098, 1977.

[4] J. D. Kim, "Extraction characteristics of heavy metals for soil washing of mine tailings-contaminated soil according to particle size distribution", J. Korean Chem. Soc., Vol. 19, No. 1, pp. 98-104, 2008.

[5] G. Bombieri and G. Depaoli, "Crown ether complexes of actinide elements (an x-ray study of the conformational change of the crown ether within the $\mathrm{UO}_{2}\left(\mathrm{NO}_{3}\right)_{2}\left(\mathrm{H}_{2} \mathrm{O}\right)_{2}$ (18-crown-6) molecule)", J. Inorg. Nucl. Chem., Vol. 40, pp. 799-802, 1978.

[6] S. S. Kim, M. Park, N. H. Hur, and J. Choi, "Development of heavy metal adsorbent utilizing natural zeolite", J. Environ. Agric., Vol. 10, No. 1, pp. 1119, 1991.

[7] T. Hayashita, J. H. Lee, S. Chen, and R. A. Bartsch, "Selective column concentration of alkali-metal cations with a crown ether carboxylic acid resin", Anal. Chem., Vol. 63, pp. 1844-1847, 1991.

[8] E. Blasius, and P. G. Maurer, "Darstellung von austauschern mit kryptanden als ankergruppen", Makromol. Chem., Vol. 178, pp. 649-657, 1977.

[9] C. Y. Lee and J. T. Kim, "Adsorption of metal ions on synthetic resin with styrene hazardous materials in water fire extinguishing agent", Appl. Chem. Eng., Vol. 21, No. 2, pp. 142-147, 2010.

[10] H. Egawa, T. Nonaka, and M. Ikari, "Preparation of macroreticular chelating resins containing dihydroxyphosphino and/or phosphono groups and their adsorption ability for uranium", J. Appl. Poly. Sci., Vol. 29, pp. 2045-2055, 1984.

[11] M. Y. Suh, T. Y. Eom, and I. S. Suh, "Chromatographic behavior of cryptand[2,2] modified resin on metal cations", Bull. Korean Chem. Soc., Vol. 8, No. 5, pp. 366-372, 1987.

[12] S. H. Kim, "Adsorption characteristics of heavy metal ions on 1-aza-18-crown-6-styrene-DVB synthetic resin", Dongshin University, Ph. D. Dissertation, Naju, Korea, 2008.

[13] K. C. Kang, S. S. Kim, M. H. Baik, S. H. Kwon, and S. W. Rhee, "Sorption of aqueous uranium(VI) ion onto a cation-exchangeable K-birnessite colloid", Anal. Sci. \& Tech., Vol. 23, No. 6, pp. 566571,2010 
[14] J. T. Kim, "Adsorption characteristics of metal ions on the macrocyclic synthetic resin adsorbent with styrene hazardous material", J. Korean Soc. Environ. Anal., Vol. 15, No. 1, pp. 35-41, 2012.

[15] C. Y. Lee and J. T. Kim, "Adsorption of metal ions on synthetic resin with styrene hazardous materials in water fire extinguishing agent", Appl. Chem. Eng., Vol. 21, No. 2, pp. 142-147, 2010.

[16] J. T. Kim, Adsorption of uranium() ion on 1-aza-12crown-4 synthetic resin with styrene hazardous material, J. Chosun Natural Sci., Vol. 6, No. 2, pp.
104-110, 2013

[17] S. M. Howdle, K. Jerabek, V. Leocorbo, P. C. Marr, and D. C. Sherrington, "Reversibly collapsible macroporous poly (styrene-divinylbenzene) resins", Polymer, Vol. 41, No. 19, pp. 7272-7277, 2000.

[18] J. A. Dean (Ed), "Lange's handbook of chemistry", 13th, McGraw-Hill Book Company, New York, pp. 9-30 9-65, 1985.

[19] C. J. Pedersen, "Crystalline salt complexes of macrocyclic polyethers", J. Am. Chem. Soc., Vol. 92, No. 2, pp. 386-391, 1970. 